\title{
Neutrophil Extracellular Traps and Acute Pancreatitis
}

\author{
Raed Madhi* \\ Department of surgery, Lund University, Sweden
}

*Corresponding author: Raed Madhi, Department of surgery, Lund University, Sweden.

Received Date: August 26, 2019

Published Date: September 10, 2019

\begin{abstract}
Leukocytes participation to the pathogenesis of acute pancreatitis is getting more appreciation and extra understanding in immune signaling and might provide potential therapeutic targets that could be a useful way to ameliorate local and systemic inflammation in acute pancreatitis (AP).

Keywords: Neutrophil; Neutrophil extracellular traps; integrins; Acute pancreatitis

Abbreviations: (AP) Acute pancreatitis; (NETs) Neutrophil Extracellular Traps; Intraperitoneal; (ICAM-1) Intercellular Adhesion Molecule 1; (MIP2/CXCL2) Macrophage Inflammatory Protein-2; (VCAM-1) Vascular Cell Adhesion Protein 1; (LFA -1) Lymphocyte Function Associate Antigen-1; (Mac-1) Macrophage Antigen-1.
\end{abstract}

\section{Introduction}

Acute pancreatitis (AP) is an acute inflammatory process of pancreatic gland that characterized by trypsinogen activation of intra acinar cells with inflammatory response can be extended to remote organs [1]. AP has been encountered in many countries with increased incidence [2,3]. In fact, the clinical manifestations of AP are variable and range from mild, with self-limiting abdominal disturbance and may go away without treatment, to severe cases that can cause life-threatening complications [4]. Normally, the complications that associated with mild case may recover within couple of days [5]. In contrast, severe case of AP can develop a local necrosis and systemic inflammation that can present in 20$30 \%$ of patients and associated with up to $40 \%$ of mortality rate [6]. Although many studies have been tried to investigate a specific therapy of AP, however, so far it is largely limited to supportive therapies. Subsequently, management of patients with AP poses this problem a great challenge to clinicians. Therefore, it is suggested that understanding the pathophysiological mechanism of AP might be a key step in treatment this disease.

Having established that trypsinogen activation, inflammation and impaired microvascular perfusion are merged components in pathophysiology of AP $[7,8]$. It is well known that activation of trypsinogen appears to be initiated in the early step which can result in auto-digestion of pancreatic tissue. Indeed, leukocytes migration and recruitment have been shown to be a hallmark of inflammation and previous studies have implicated leukocytes in development of AP $[9,10]$.

\section{Role of Neutrphil in AP}

Neutrophils are most abundant type of granulocytes and represent the first defense line of host immune response [11]. These cells are originally generated by bone marrow stem cells. Neutrophils have short live and characterized by their ability to leak from circulation out into damaged tissue [12]. During inflammation of AP, it has been observed that chemoattractant can be released into circulation and can cause neutrophils rolling and migration into pancreatic tiusse [13]. For example, previous studies have found that inflamed pancreas can release chemokines, such as CXCL1 and CXCL2 that direct the neutrophils to site of inflammation $[14,15]$. CXCR2 is a receptor expressed on murine neutrophil and has high affinity for CXCL1 and CXCL2 $[16,17]$. This receptor has observed to be a critical for neutrophil infiltration in the pancreas [18].

Furthermore, it has been observed that P-selectin has a key role in neutrophil rolling and recruitment in severe pancreatitis [19]. Indeed, a previous study has demonstrated that targeting P-selectin showed a significant reduction in the inflammation of AP 19. In addition, ICAM-1 and vascular cell adhesion protein 1 (VCAM-1) are other two important molecules that involved in leukocyte adhesion [20]. These proteins have been found to mediate 
leukocyte migration via binding with their ligands on leukocytes such as lymphocyte function associate antigen-1 (LFA-1) (CD11a/ CD18), and macrophage antigen-1 or (Mac-1) (CD11b/CD18) on neutrophils $[21,22]$ as showed in (Figure 1).

During the development of local tissue injury proinflammatory compounds e.g. MIP-2, are synthesised and released. Circulating immune cells encountering such secreted substances are triggered to express adhesion molecules. The leukocyte endothelium interaction reduces leukocyte velocity, enabling rolling and subsequently firm adhesion. These mechanisms are relying on specific subsets of adhesion molecules such as selectins or integrins. Chemotaxis along a concentration gradient directs the inflammatory cells to the site of injury. Having established that activated trypsin has a key role in activation of trypsinogen by proteolytic cleavage and in turn trypsin can rapidly activates other pancreatic proenzymes [23]. In fact, a previous study has found that the initial step of trypsinogen activation is independent on neutrophils, however, later on trypsinogen activation showed to be dependent on neutrophils 9.

\section{Role of Neutrophil Extracellular Traps in AP}

Agrowing line of evidences has shown that neutrophils consider the first defense line against different infectious invaders such as bacteria, fungi and protozoa. During the inflammation, neutrophils chemoattracted and migrate the blood vessels toward the inflamed tissue by following the chemotactic compounds [24,25]. Activated neutrophils can use various mechanisms to kill invading pathogen. For example, neutrophils have been observed to release web-like structures called neutrophil extracellular traps (NETs) [26,27]. Structurally, NETs consist of DNA, histones, neutrophil elastase and myeloperoxidase (MPO) as well as embedded antimicrobial granular proteins $[28,29]$. NETs are released to extracellular spaces by process called netosis which is another type of cell death program that results in decondensation of neutrophil chromatin [30]. In fact, NETs consider as sword with two edges. On one hand, NETs have shown to provide the host with a defense mechanism against invading pathogens by trap and kill them [28]. On the other hand, it has been shown that NETs have a potent inflammatory role in various inflammatory diseases such as rheumatoid arthritis (RA) [31], vascular disorder [32], inflammatory lung diseases [33]. Moreover, Merza et al have observed for the first-time formation of NETs in the inflamed pancreas [34], as shown in (Figure 2).

1. Scanning electron microscopy showing extracellular web-like structures in the pancreas from a mouse exposed to taurocholate. Scale bar: $5 \mathrm{~mm}$.

2. A higher magnification of the indicated area of interest from (Figure 1) showing fibrillar structures compatible with NETs in the inflamed pancreas. Scale bar: $2 \mathrm{~mm}$.

3. Transmission electron microscopy of the indicated area of interest from (Figure 1) incubated with gold-labeled antihistone 2B (large gold particles) and anti-elastase (small gold particles) antibodies. Scale bar: $0.25 \mathrm{~mm}$ [35].

Mechanically, the authors have found that peptide arginine deminase (PAD4) regulates NETs formation and inflammation in AP 35. Moreover, they found also that protein signaling also regulate NET formation in AP. for example, they found that c-abl kinase regulates NETs formation via controlling reactive oxygen species (ROS) generation 13, as showed in (Figure 3). Quantification of ROS formation in isolated neutrophils by flow cytometry. TNF- $\alpha$ stimulation of neutrophils with or without GZD824. No stimulated neutrophils served as a control. Representative histogram of ROS generation and aggregate data. Data represent mean \pm SEM and $\mathrm{n}=$ $\# \mathrm{P}<0.05$ versus control and ${ }^{*} \mathrm{P}<0.05$ versus vehicle $+\mathrm{TNF}-\alpha[35]$.

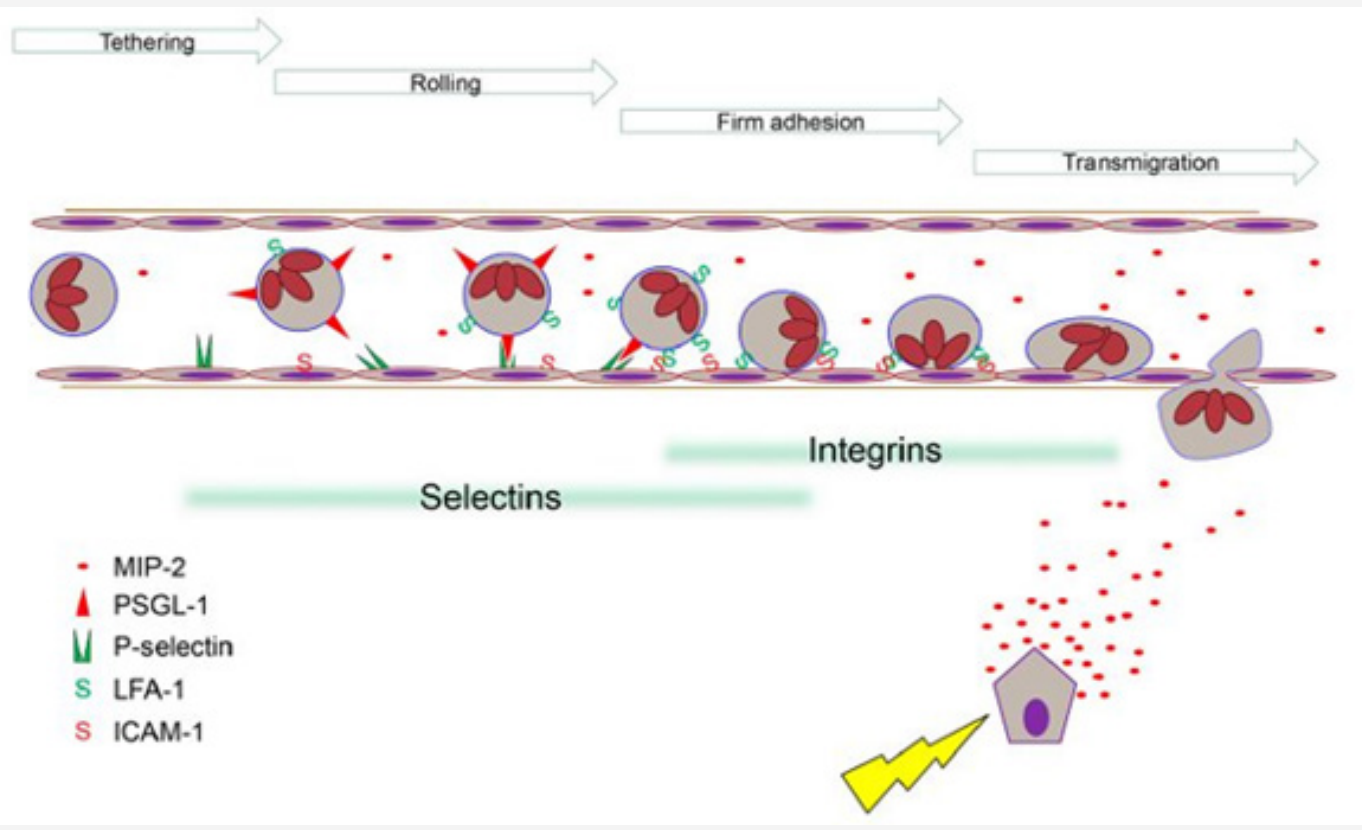

Figure 1: Diagram of Leukocyte extravasation. 


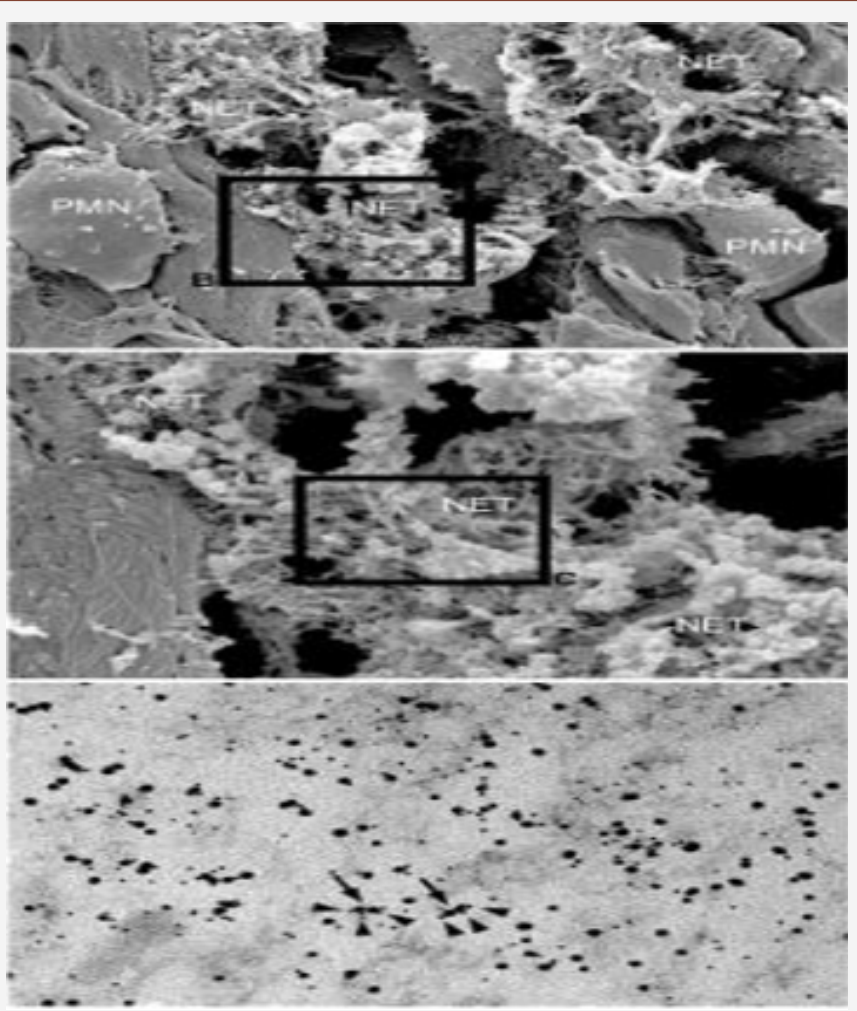

Figure 2: NET formation in AP.
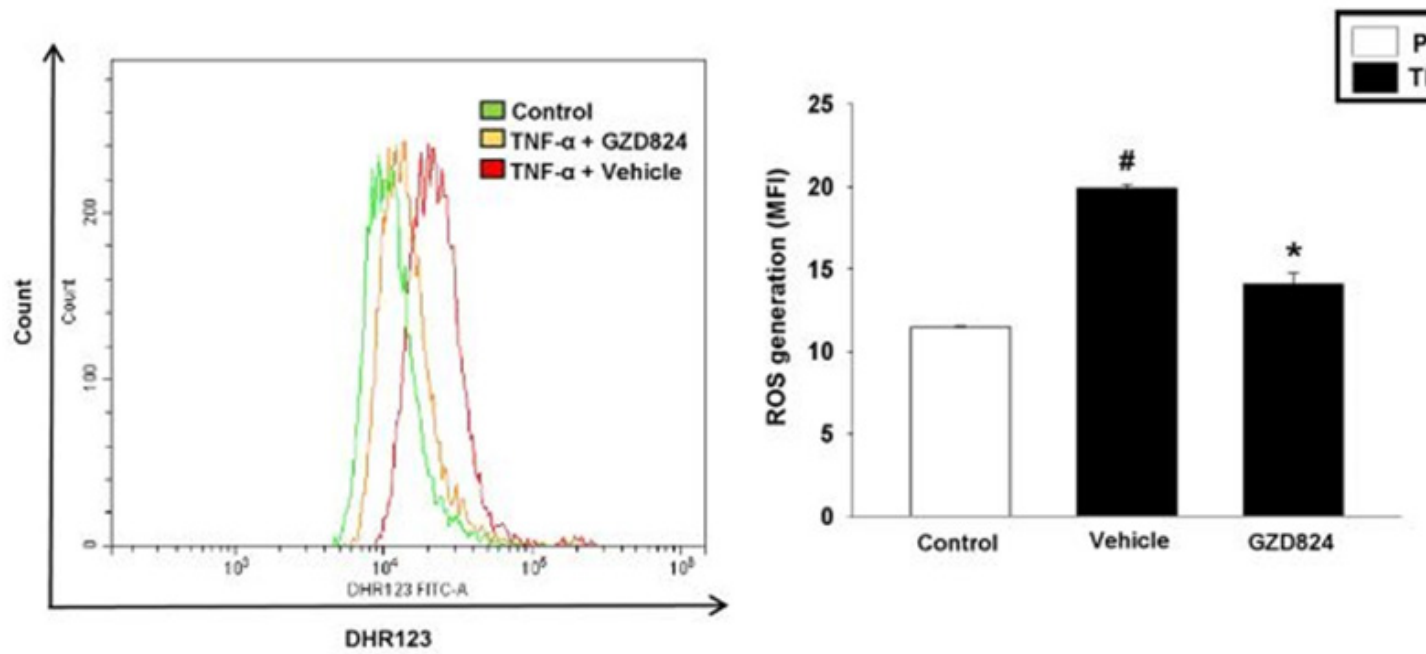

Figure 3: ROS formation in Neutrophils.

\section{Acknowledgement}

None.

\section{Conflict of Interest}

No conflict of interest.

\section{References}

1. Petrov MS, Shanbhag S, Chakraborty M, Phillips AR, Windsor JA (2010). Organ failure and infection of pancreatic necrosis as determinants of mortality in patients with acute pancreatitis. Gastroenterology 139: 813-820.

2. Munsell MA, Buscaglia JM (2010) Buscaglia JM Acute pancreatitis. J Hosp Med 5: 241-250.

3. Bradley EL (1993) A clinically based classification system for acute pancreatitis. Summary of the International Symposium on Acute
Pancreatitis, Atlanta, Ga, September 11 through 13, 1992. Arch Surg 128: 586-590.

4. Bollen TL, Van Santvoort HC, Besselink MG, van Es WH, Gooszen HG, et al. (2007) Update on acute pancreatitis: ultrasound, computed tomography, and magnetic resonance imaging features. Semin Ultrasound CT MR 28: 371-383.

5. Banks PA, Freeman ML (2006) Practice Parameters Committee in acute pancreatitis. Am J Gastroenterol 101: 2379-2400.

6. Van Acker GJ, Perides G, Steer ML (2006) Co-localization hypothesis: a mechanism for the intrapancreatic activation of digestive enzymes during the early phases of acute pancreatitis. World J Gastroenterol 12: 1985-1990.

7. Wang GJ, Gao CF, Wei D, Wang C, Ding SQ (2009) Acute pancreatitis: etiology and common pathogenesis. World J Gastroenterol 15: 14271430. 
8. Zhang XP, Li ZJ, Zhang J (2009) Inflammatory mediators and microcirculatory disturbance in acute pancreatitis. Hepatobiliary Pancreat Dis Int 8: 351-357.

9. Abdulla A, Awla D, Thorlacius H, Regner S (2011) Role of neutrophils in the activation of trypsinogen in severe acute pancreatitis. J Leukoc Biol 90: 975-982.

10. Awla D, Abdulla A, Zhang S, Roller J, Menger MD, et al. (2011) Lymphocyte function antigen-1 regulates neutrophil recruitment and tissue damage in acute pancreatitis. Br J Pharmacol 163: 413-423.

11. Ermert D, Niemiec MJ, Röhm M, Glenthøj A, Borregaard N, et al. (2013) Candida albicans escapes from mouse neutrophils. J Leukoc Biol 94: 223-236.

12. Mansfield C (2012) Pathophysiology of acute pancreatitis: potential application from experimental models and human medicine to dogs. J Vet Intern Med 26: 875-887.

13. Madhi R, Rahman M, Morgelin M, Thorlacius H (2019) c-Abl kinase regulates neutrophil extracellular trap formation, inflammation, and tissue damage in severe acute pancreatitis. J Leukoc Biol 106: 455-466.

14. Bhatia M, Ramnath RD, Chevali L, Guglielmotti A (2005) Treatment with bindarit, a blocker of MCP-1 synthesis, protects mice against acute pancreatitis. Am J Physiol Gastrointest Liver Physiol 288: G1259-1265.

15. Arango Duque G, Descoteaux A (2014) Macrophage cytokines: involvement in immunity and infectious diseases. Front Immunol 5: 491.

16. Adams DH, Lloyd AR (1997) Chemokines: leucocyte recruitment and activation cytokines. Lancet 349: 490-495

17. Cacalano G, Lee J, Kikly K, Ryan AM, Pitts Meek S, et al. (1994) Neutrophi and $B$ cell expansion in mice that lack the murine IL-8 receptor homolog. Science 265: 682-684.

18. Bhatia M, Hegde A (2007) Treatment with antileukinate, a CXCR2 chemokine receptor antagonist, protects mice against acute pancreatitis and associated lung injury. Regul Pept 138: 40-48.

19. Hartman H, Abdulla A, Awla D, Lindkvist B, Jeppsson B, et al. (2012) P-selectin mediates neutrophil rolling and recruitment in acute pancreatitis. Br J Surg 99: 246-255.

20. Barreiro 0, Sanchez Madrid F (2009) Molecular basis of leukocyteendothelium interactions during the inflammatory response. Rev Esp Cardiol 62: 552-562.

21. Kakkar AK, Lefer DJ (2004) Leukocyte and endothelial adhesion molecule studies in knockout mice. Curr Opin Pharmacol 4: 154-158.

22. Radi ZA, Kehrli ME, Ackermann MR (2001) Cell adhesion molecules, leukocyte trafficking, and strategies to reduce leukocyte infiltration. J Vet Intern Med 15: 516-529.
23. Pezzilli R (2009) Pharmacotherapy for acute pancreatitis. Expert Opin Pharmacother 10: 2999-3014.

24. Wang J (2018) Neutrophils in tissue injury and repair. Cell Tissue Res 371: 531-539.

25. Wang HH, Tang AM, Chen L, Zhou MT (2012) Potential of sivelestat in protection against severe acute pancreatitis-associated lung injury in rats. Exp Lung Res 38: 445-452.

26. Fuchs TA, Abed U, Goosmann C, Hurwitz R, Schulze I, et al. (2007) Novel cell death program leads to neutrophil extracellular traps. J Cell Biol 176: 231-241.

27. Brinkmann V, Reichard U, Goosmann C, Fauler B, Uhlemann Y, et al. (2004) Neutrophil extracellular traps kill bacteria. Science 303: 15321535.

28. Byrd AS, O Brien XM, Johnson CM, Lavigne LM, Reichner JS (2013) An extracellular matrix-based mechanism of rapid neutrophil extracellular trap formation in response to Candida albicans. J Immunol 190: 41364148.

29. Iba T, Hashiguchi N, Nagaoka I, Tabe Y, Murai M (2013) Neutrophil cell death in response to infection and its relation to coagulation. J Intensive Care 1: 13.

30. Gardiner EE, Andrews RK (2012) Neutrophil extracellular traps (NETs) and infection-related vascular dysfunction. Blood Rev 26: 255-259.

31. Hakkim A, Fürnrohr BG, Amann K, Laube B, Abed UA, et al. (2010) Impairment of neutrophil extracellular trap degradation is associated with lupus nephritis. Proc Natl Acad Sci USA 107: 9813-9818.

32. Cheng OZ, Palaniyar N (2013) NET balancing: a problem in inflammatory lung diseases. Front Immunol 4: 1.

33. Clark SR, Ma AC, Tavener SA, Mc Donald B, Goodarzi Z, et al. (2007) Platelet TLR4 activates neutrophil extracellular traps to ensnare bacteria in septic blood. Nat Med 13: 463-469.

34. Merza M, Hartman H, Rahman M, Hwaiz R, Zhang E, et al. (2015) Neutrophil Extracellular Traps Induce Trypsin Activation, Inflammation, and Tissue Damage in Mice with Severe Acute Pancreatitis. Gastroenterology 149: 1920-1931.

35. Madhi R, Rahman M, Taha D, Morgelin M, Thorlacius H (2019) Targeting peptidyl arginine deiminase reduces neutrophil extracellular trap formation and tissue injury in severe acute pancreatitis. J Cell Physiol 234: 11850-11860. 